\title{
A Developmentally Regulated Chicken Neuronal Protein Associated with the Cortical Cytoskeleton
}

\author{
Timothy E. Allsoppa and Diana J. Moss \\ M.R.C. Cell Biophysics Unit and Department of Biophysics Cell and Molecular Biology, Kings College (K.Q.C.), London \\ WC2B 5RL, United Kingdom
}

\begin{abstract}
Monoclonal antibody 3D5 recognizes a single component of the neuronal membrane skeleton isolated from the chicken embryo brain. The 3D5 antigen is highly enriched in the CNS, and smaller amounts are found in the PNS. It is also present in non-neural tissues, but this is due to peripheral innervation. The biochemical and molecular properties of the 3D5 antigen are very similar to those of the previously described mammalian protein B-50 (Zwiers et al., 1985)/GAP 43 (Jacobson et al., 1986)/pp46 (Ellis et al., 1985)/F 1 (Chan et al., 1986), and include anomalous SDS gel migration, acidic isoelectric point, and extraction from the cytoplasmic side of the plasma membrane only under extremely alkaline conditions. The 3D5 antigen is also developmentally regulated, with maximum expression in brain occurring at E14-E16, after which levels decrease approximately 4 -fold in the adult. Immunofluorescence staining of cultured neurons shows that the 3D5 antigen is located in all parts of the cell but is particularly enriched in the growth cone and the growth cone filopodia. As the 3D5 antigen is enriched in the membrane skeleton, we suggest that this protein is involved in an association between the actin-containing cytoskeleton and the plasma membrane.
\end{abstract}

Neurons, in common with most cells, possess an actin network closely associated with the plasma membrane. This cortex or membrane skeleton serves many diverse functions during neuronal development and in mature neurons. For example, transmission of the contractile force required for growth cone locomotion and the generation and subsequent maintenance of the cell's highly asymmetric shape depend, at least partly, on a membrane-associated cytoskeleton. Although little is known about the structure of the neuronal membrane skeleton, it is complex and varies from region to region within an individual neuron (Lazarides and Nelson, 1983). For these reasons, several different molecules may be responsible for interactions between

\footnotetext{
Received July 24, 1987; revised Apr. 18, 1988; accepted May 20, 1988

We thank Dr. Dennis Bray, in whose laboratory this work was carried out, for his valuable advice and encouragement throughout this study. Thanks are due to Clive Thomas, Dr. James Bamburg, Kevin Chapman, and Peter Mayhew. T.E.A. is supported by an M.R.C. Studentship grant, and D.J.M. is a Royal Society 1983 University Research Fellow.

Correspondence should be addressed to Diana J. Moss, M.R.C. Cell Biophysics Unit and Department of Biophysics Cell and Molecular Biology, Kings College, 26-29 Drury Lane, London WC2B 5RL, UK.

a Present address: Max-Planck-Institut für Entwicklungsbiologie, Abteilung Physikalische Biologie, D-7400 Tubingen 1, FRG.

Copyright (C) 1989 Society for Neuroscience $0270-6474 / 89 / 010013-12 \$ 02.00 / 0$
}

the cytoskeleton and the membrane. Some of these are similar to those found in other cell types, but some may be specific to neurons.

Components related to erythrocyte ankyrin, spectrin, and band 4. 1 have been identified in neurons, although their precise function in this more complex cell has yet to be elucidated (Bennett, 1985; Lazarides and Nelson, 1985). For example, both brain ankyrin and synapsin (onc of two 4.1-like proteins) interact with microtubules, and synapsin can associate with secretory vesicles as well as plasma membranes (Bennett et al., 1985), suggesting that these proteins have additional roles to those already defined in the erythrocyte membrane skeleton.

A second, partially characterized association between actin filaments and the membrane occurs in the focal adhesions of fibroblasts. Stress fibers are linked via proteins such as $\alpha$-actinin, vinculin, and talin to an integral membrane protein complex (integrin) that binds to ECM components (Horwitz et al., 1985, 1986). A glycoprotein complex antigenically and functionally related to integrin has recently been identified in peripheral neurons (Bozyczko and Horwitz, 1986). As in the case of fibroblasts and muscle cells, evidence suggests that integrin may be a receptor for fibronectin and laminin. $\alpha$-Actinin is well characterized from nervous tissue (Duhaiman and Bamburg, 1984), although talin and vinculin have yet to be identified. Thus, less highly organized structures similar to focal adhesions may occur in the growth cones of neurons.

We are interested in components of the neuronal membrane skeleton, especially those that may be involved in growth cone locomotion and the formation of the actin cortex. A detergentinsoluble membrane skeleton has been isolated from chicken neurons and shown to consist of 2 or more concanavalin A (Con A)-binding glycoproteins, actin and several additional proteins (Moss, 1983). One glycoprotein (GP130) has heen partially characterized and shown to be restricted to nervous tissue and may be specific to neurons (Ranscht et al., 1984). In order to characterize additional components of the neuronal membrane skeleton, we have raised a monoclonal antibody that recognizes a single component from the membrane skeleton of apparent molecular weight $55 \mathrm{kDa}$ by $10 \%$ SDS-PAGE. This protein - which is enriched in, and may be specific for, neurons-is developmentally regulated. From a study of its biochemical and molecular properties we identify the protein as being the chicken equivalent of a well-characterized mammalian protein (B-50/ GAP 43/pp46/F1) that is associated with neuronal growth. Additionally, we describe here its characterization as a component of the neuronal membrane skeleton. 


\section{Materials and Methods}

\section{Materials}

All conjugated antibodies were obtained from Amersham International. The anti-brain spectrin antibody was kindly donated by A. Baines. The Con A-Sepharose was made from activated Sepharose (Pharmacia) and Con A (BDH). Aurodye colloidal gold reagent was obtained from Janssen Life Sciences Products.

\section{Methods}

Preparation of the detergent-insoluble cytoskeletal material. This was performed essentially as described previously (Kanscht et al., 1984), with the following modifications. Brains from embryonic day (E) 1618 embryos were homogenized at $4^{\circ} \mathrm{C}$ in buffer $\mathrm{A}(0.2 \mathrm{~mm}$ DTT, 10 $\mathrm{mm}$ Tris-Cl, $\mathrm{pH}$ 7.6) with $1 \mathrm{~mm}$ phenyl methyl sulfonyl fluoride (PMSF), Nonidet P-40 (1-5\%) to give a 5:1 (wt/wt) detergent-to-protein ratio, 1 $\mu \mathrm{g} / \mathrm{ml}$ leupeptin and pepstatin A; $10 \mu \mathrm{g} / \mathrm{ml} N$-benzoyl-t-arginine methyl ester, $p$-tosyl-L-arginine methyl ester, soybean trypsin inhibitor, and L-1-tosylamide-2-phenylethylchloromethyl ketone. The detergent-insoluble material was pelleted for $30 \mathrm{~min}$ at $100,000 \times g\left(4^{\circ} \mathrm{C}\right)$ and resuspended in buffer A containing 10\% wt/vol sucrose. Fractions were separated for $3 \mathrm{hr}$ at $100,000 \times \mathrm{g}$ on a discontinuous sucrose gradient consisting of layers 50,30 , and $10 \%$ sucrose in buffer $A$. The membraneskeleton fraction collects at the $10-30 \%$ interface on this gradient. This material was collected, diluted in buffer A, and pelleted at $100,000 \times$ $g$. The material resuspended in buffer $A$ is termed the "membrane skeleton." Enriched membrane skeleton fractions were prepared by chromatography on DEAE-cellulose in $0.2 \%$ Empigen BB (Albright \& Wilson Ltd., Whitehaven, Cumbria) as described previously.

Protein concentrations were determined as described (Bramhall et al., 1969) using BSA as a standard. Con A binding glycoproteins were detected by SDS-PAGE with ${ }^{125}$ I-Con A overlay, as previously described (Moss, 1983).

Monoclonal antibody production. BALB/C mice were immunized initially with $0.2 \mathrm{mg}$ of membrane skeleton in Freund's complete adjuvant, followed by 2 injections of $0.1 \mathrm{mg}$ of enriched membrane skeletal material in incomplete adjuvant and an injection without adjuvants. All injections were intraperitoneal. The final injection, $3 \mathrm{~d}$ before sacrifice, was $0.1 \mathrm{mg}$ of enriched membrane skeleton material into the tail vein. Spleen cells from one mouse were fused with hypoxanthine aminopterine-thymidine-sensitive SP2/0-Ag14 (Shulman et al., 1978) myeloma cells according to published procedures (Koehler and Milstein, 1975; Galfre et al., 1977). The 3D5 hybridoma line was selected for its ability to stain cultured sensory neurons in immunofluorescence and its reactivity on immunoblots against a component of the membrane skeleton fraction. The cells were subcloned twice by limiting dilution on macrophage feeder layers. Ascites fluid was produced in pristane-treated $\mathrm{BALB} / \mathrm{C}$ exbreeders and subjected to precipitation with $50 \%$ ammonium sulfate before use.

Cell culture. Cultures of sympathetic and dorsal root ganglion neurons for immunofluorescence were prepared as described (Ranscht et al., 1984). Briefly, sensory or sympathetic ganglia were dissected aseptically from E10-11 chicken embryos into Hanks balanced salt solution without $\mathrm{Ca}^{2+}$ or $\mathrm{Mg}^{2+}$. After trypsinization $(0.25 \%$ trypsin in HBSS without $\mathrm{Ca}^{2+}$ or $\mathrm{Mg}^{2+}$ ) for $30 \mathrm{~min}$ at $37^{\circ} \mathrm{C}$, the ganglia were dissociated into single cells and grown in L15 medium (Gibco) containing $10 \%$ fetal calf serum, $0.5 \%$ methylcellulose, $100 \mathrm{U} / \mathrm{ml}$ penicillin, $100 \mu \mathrm{g} / \mathrm{ml}$ streptomycin, $2 \mathrm{~mm}$ glutamine, and $0.6 \mathrm{~g}$ /liter glucose and NGF. Cells were seeded onto poly(L-lysine) (MW 30,000-70,000), carbon-coated glass coverslips.

Indirect immunofluorescence. Indirect immunofluorescence was carried out on primary cultures from the PNS, the cells being grown for $24 \mathrm{hr}$. Cells were fixed prior to staining using methanol at $-20^{\circ} \mathrm{C}$. Cells were incubated sequentially with 3D5 (ascites fluid at 1:200 dilution), biolinylated sheep anti-mouse $\operatorname{Ig}(1: 75)$ and then a streptavidin-Texas Red conjugate (1:75). All incubations were in PBS containing $1 \%$ BSA for $45 \mathrm{~min}$ at room temperature in a humidified chamber. After each incubation the cells were washed by immersion through 5 changes of PBS.

F-actin was visualized using rhodamine phalloidin (Sigma; $10 \mu \mathrm{g} / \mathrm{ml}$ ) on cells previously fixed and permeabilized with a $0.25 \%$ glutaraldehyde, $0.1 \%$ Triton in PBS. Autofluorescence was reduced with $100 \mu \mathrm{g} / \mathrm{ml}$ $\mathrm{NaBH}_{4}$ in PBS at $4^{\circ} \mathrm{C}$, prior to treatment with rhodamine phalloidin. Following incubation with the appropriate fluorochrome conjugate, the coverslips were mounted with Gelvatol containing DABCO (Aldrich).
Staining was analyzed under a Zeiss fluorescence microscope with appropriate filters for rhodamine.

Mounting and staining of tissue sections. Dissected pieces of small intestine from a freshly killed E17 chicken embryo were fixed for $1 \mathrm{hr}$ in $4 \%(\mathrm{wt} / \mathrm{vol})$ paraformaldehyde EM (Agar Aids) in $0.12 \mathrm{~m}$ phosphate buffer, $\mathrm{pH}$ 7.4. The tissue pieces were taken through a series of sucrose solutions from 6 to $18 \%(\mathrm{wt} / \mathrm{vol})$ prior to mounting. The tissue pieces were then trimmed to an appropriate size, orientated on the sectioning block, and frozen in Tissue-Tek II OCT compound (Miles) on dry ice. Mounted blocks were stored at $-70^{\circ} \mathrm{C}$ until use. Frozen sections, 11 $\mu \mathrm{m}$, were cut on a Bright cryostat model OTF, and the sections were adhered to gelatin/chromate-coated glass slides. The tissue sections were treated with $0.1 \mathrm{M}$ glycine, pH 7.4 , for $15 \mathrm{~min}$ at room temperature, followed by $10 \%(\mathrm{vol} / \mathrm{vol})$ donkey serum in PBS containing $0.05 \%$ Tween 20 for $30 \mathrm{~min}$ at room temperature. Sections were then incubated sequentially in 3D5 ascites fluid (1:200), biotinylated sheep anti-mouse $\lg (1: 75)$, Streptavidin Texas Red conjugate (1:75). All incubations were performed in PBS containing 5\% (wt/vol) BSA, 0.05\% Tween 20, and at room temperature in a humidified chamber. Sections were washed in $0.05 \%$ Tween 20 -containing PBS buffer between incubations. Sections were mounted in Gelvatol and viewed under oil immersion using a ×25 objective.

SDS-PAGE and isoelectric focusing. SDS-PAGE was performed as described by Matsudaira and Burgess (1978), using $10 \times 10.5 \mathrm{~cm}$ glass plates, $0.5-\mathrm{mm}$-thick spacers, and the discontinuous buffer system of Laemmli (1970). Molecular weight standards used were as follows: $\beta$-galactosidase, 116,000; phosphorylase b, 95,000; BSA, 66,000; bovine brain tubulin, 53,000; egg ovalbumin, 45,000; carbonic anhydrase, 29,000; and trypsin inhibitor, 20,100. Acrylamide monomer concentrations used varied from 7 to $15 \%$. Isoelectric focusing was performed as described by O'Farrell (1975), using tube gels $7.5 \mathrm{~cm}$ long by $1.2 \mathrm{~mm}$ in diameter. Polyacrylamide gels were either stained with Comassie Brilliant blue or silver-stained using the method of Morrisey (1981).

Detection of antibody binding to proteins separated by SDS-PAGE. Proteins separated by SDS-PAGE on minigels $(0.5 \mathrm{~mm}$ thick) were transferred electrophoretically to nitrocellulose paper (Towbin et al., 1979). Nonspecific binding of proteins to the membranes was reduced with an initial overnight washing step in $10 \mathrm{~mm}$ Tris-Cl, pH 8.4, 150 $\mathrm{mM} \mathrm{NaCl}, 0.05 \%$ (vol/vol) Tween $20,0.1 \% \mathrm{NaN}_{3}$ (buffer B). The 3D5 antigen was detected by incubation with 3D5 (ascites fluid at initial dilution of 1:100 or culture supernatant used without dilution), followed by rabbit anti-mouse $\mathrm{Ig}(1: 100)$ in buffer B with $3 \mathrm{mg} / \mathrm{ml}$ BSA and donkey anti-rabbit HRP conjugate $(1: 200)$ in buffer $B$ without azide. All incubations were carried out for $1 \mathrm{hr}$ at room temperature and were followed by 45 min washes with at least 5 changes of buffer B. Azidefree buffer $B$ was used before and after incubations with HRP-coupled components. Labeled protein bands were detected using $0.5 \mathrm{mg} / \mathrm{ml}$ diaminobenzidine in $1 \%$ DMSO, $\mathrm{PBS}$ at $\mathrm{pH} 7.4$ containing $0.02 \% \mathrm{H}_{2} \mathrm{O}_{2}$, with $0.03 \%(\mathrm{wt} / \mathrm{vol}) \mathrm{CoCl}_{2}$ enhancement. The GP130 was detected on immunoblots using a rabbit polyclonal antisera, the donkey anti-rabbitHRP conjugate, and $0.02 \%$ 3-amino-9-ethylcarbazole in $50 \mathrm{~mm}$ acetate buffer, $\mathrm{pH} 5$, containing $0.93 \% \mathrm{H}_{2} \mathrm{O}_{2}$.

In some cases proteins bound to nitrocellulose sheets were stained with Amido black $(0.1 \% \mathrm{wt} / \mathrm{vol})$ in $50 \%$ (vol/vol) methanol, $10 \%$ (vol $/$ vol) glacial acetic acid. Proteins separated by 2 -dimensional gel electrophoresis and transferred to nitrocellulose paper were stained with the Aurodye colloidal gold reagent.

Comparative amounts of the 3D5 antigen in different samples were quantitated by densitometry of labeled bands on immunoblots using reflectance mode on a Joyce Loebl Chromoscan 3 . This method proved reliable only for comparison of relative amounts on single immunoblots. Areas under peaks were quantitated using an area-integrating program on a PDP $11 / 44$.

Extraction of brain membranes with $\mathrm{NaOH}$. Brain membranes were prepared from E16-18 chicken brains, essentially as described by Matus (1978). E1 8 brains were homogenized in 0.32 m sucrose, $1 \mathrm{mM} \mathrm{PMSF,}$ 2 mM EDTA, $\mathrm{pH} 7.6$, and following differential centrifugation, the pellet was washed once with $0.32 \mathrm{M}$ sucrose and resuspended in a minimum volume of $0.32 \mathrm{M}$ sucrose; the membrane vesicles were lyzed by the addition of a 10 -fold excess of $10 \mathrm{~mm}$ Tris- $\mathrm{Cl}, \mathrm{pH} 7.6$, with protease inhibitors at $4^{\circ} \mathrm{C}$. The membranes were spun at $100,000 \times g$ for $30 \mathrm{~min}$ at $4^{\circ} \mathrm{C}$, washed once with $10 \mathrm{~mm}$ Tris-Cl pH 7.6, $2 \mathrm{~mm}$ EDTA, $0.02 \%$ $\mathrm{NaN}_{3}$, and stored in this buffer at $-70^{\circ} \mathrm{C}$ until use. Membranes were extracted with $0.1 \mathrm{M} \mathrm{NaOH}$ for $30 \mathrm{~min}$ at $4^{\circ} \mathrm{C}$ and spun at $200,000 \times$ $g$ for $30 \mathrm{~min}$, and the supernatant was neutralized with $1 \mathrm{M}$ Tris-Cl, pH 7.6. 
A

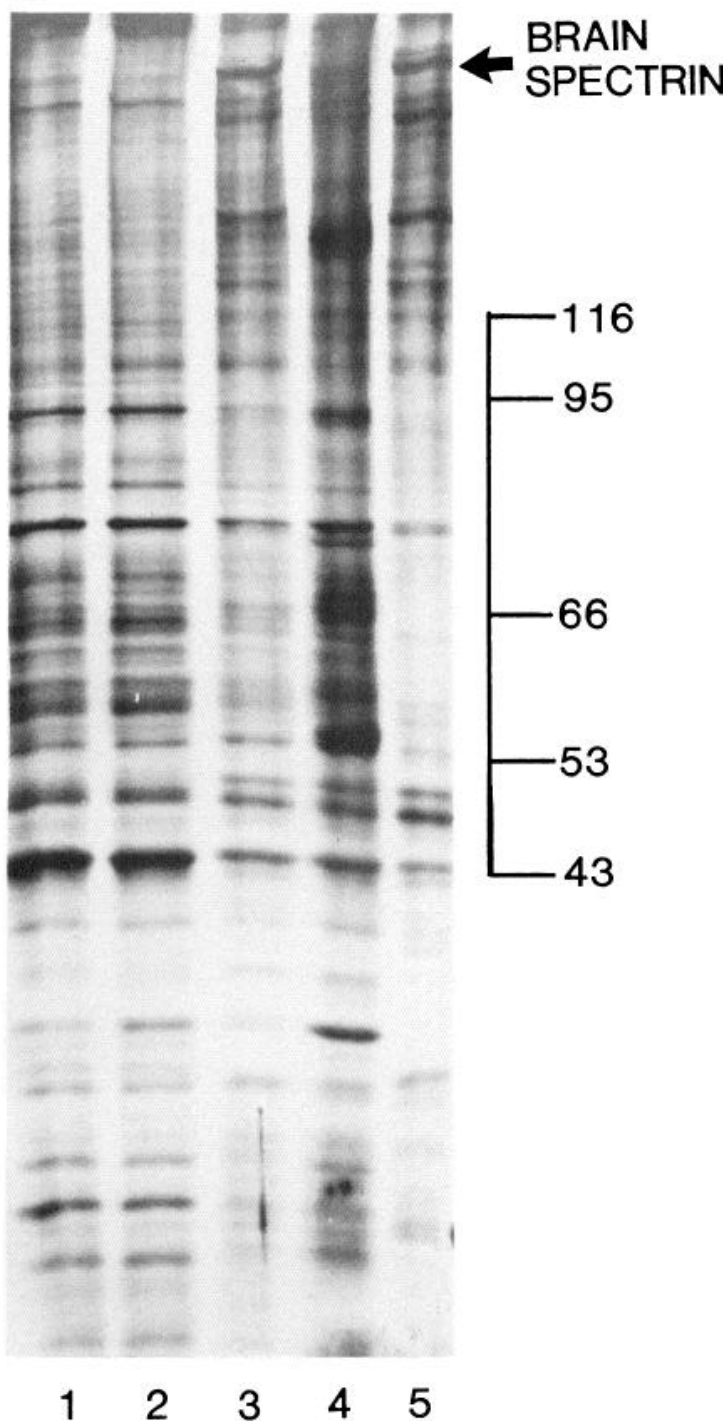

B

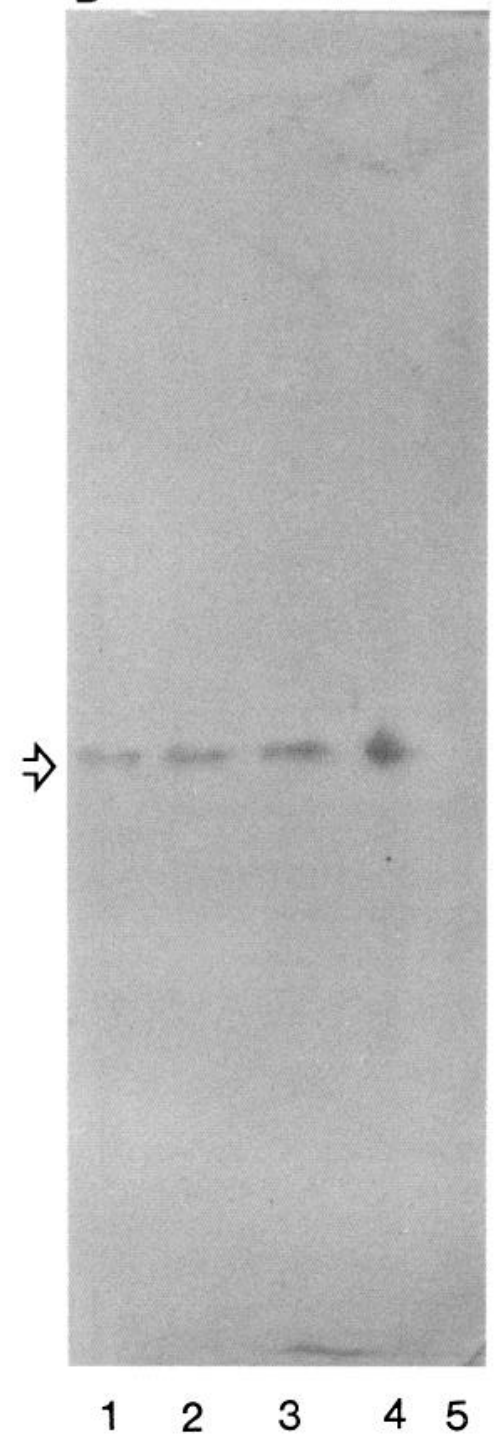

Figure 1. Enrichment of the 3D5 antigen in the neuronal membrane skeleton. Detergent extracted material from E18 chick brains was fractionated on a discontinuous sucrose gradient and samples analyzed by $9 \%$ SDS-PAGE as described in Materials and Methods. $A$, Silver staining. $B$, Western blot probed with the 3D5 monoclonal antibody. Samples are as follows: 1 , crude homogenate; 2 , detergent soluble; 3 , detergent insoluble; 4 , membrane skeleton (10-30\% sucrose interface material); 5 , material sedimenting through $50 \%$ sucrose. The arrowhead marks the position of brain spectrin, and the open arrowhead indicates the 3D5 antigen.
Con $A$ affinity chromatography. Membrane skeletal material was dissociated with $0.1 \%$ SDS and applied to a $10 \mathrm{ml}$ Con A affinity column previously equilibrated with $50 \mathrm{~mm}$ Tris- $\mathrm{Cl} \mathrm{pH} 7.6,150 \mathrm{~mm} \mathrm{NaCl}, 0.5$ mм $\mathrm{CaCl}_{2}, 0.5 \mathrm{~mm} \mathrm{MnSO}_{4}, 0.02 \% \mathrm{NaN}_{3}, 0.1 \% \mathrm{SDS}$ (buffer C). The column was washed with 2 column volumes of buffer $\mathrm{C}$ and then with 3 column volumes of buffer $\mathrm{C}$ containing $0.5 \mathrm{M} \mathrm{NaCl}$. Con A binding glycoproteins were eluted with buffer $\mathrm{C}$ containing $0.25 \mathrm{M}$ methyl- $\alpha$-Dmannopyranoside. Protein-containing fractions were analyzed by SDSPAGE and probed with ${ }^{125}$ I-Con A or the 3D5 monoclonal and an antiGP130 polyclonal antisera.

\section{Results}

\section{Monoclonal antibody $3 D 5$ recognizes a component of the} membrane skeleton of neurons

A monoclonal antibody 3D5 was obtained (as described in Materials and Methods) from a mouse immunized initially with the membrane skeleton fraction from E10-13 chick embryo brains and later with an "enriched" membrane skeleton fraction obtained by ion-exchange chromatography. 3D5 recognizes a single protein of apparent molecular weight $55 \mathrm{kDa}$ on $10 \%$ SDS-PAGE. As shown in Figure 1, the 3D5 antigen was most abundant in the detergent-insoluble fraction from brain and was found to accumulate in the membrane skeleton fraction isolated from the $10-30 \%$ sucrose interface. This fraction also contains GP130, actin, and about 20 other polypeptides. Quantitation of Western blots showed approximately a 10 -fold enrichment of the 3D5 antigen in the membrane skeleton compared with a whole brain homogenate. The 3D5 antigen could be clearly identified on silver-stained 9\% SDS-PAGE, and it appeared to be a major component of the membrane skeleton, although the appropriate band stained poorly with Coomassie and was hard to detect on equivalent Coomassie-stained SDS-PAGE.

By an immunological criterion the 3D5 antigen is unrelated to tubulin or vimentin. Polyclonal antisera against chicken tubulin and vimentin failed to detect a component corresponding to the 3D5 antigen in the membrane skeleton fraction (data not shown). A high-molecular-weight doublet that reacts with antibrain spectrin antisera, seems to be conspicuously less abundant in the membrane skeleton than in the material sedimenting through the $50 \%$ sucrose in the sucrose gradient, which corresponds to the bulk of the cytoskeleton (Fig. 1). The determinant recognized by the 3D5 monoclonal antibody is chicken specific, as the antibody does not cross-react with neural tissue from mammalian, amphibian, or piscean sources. 


\section{CNS}

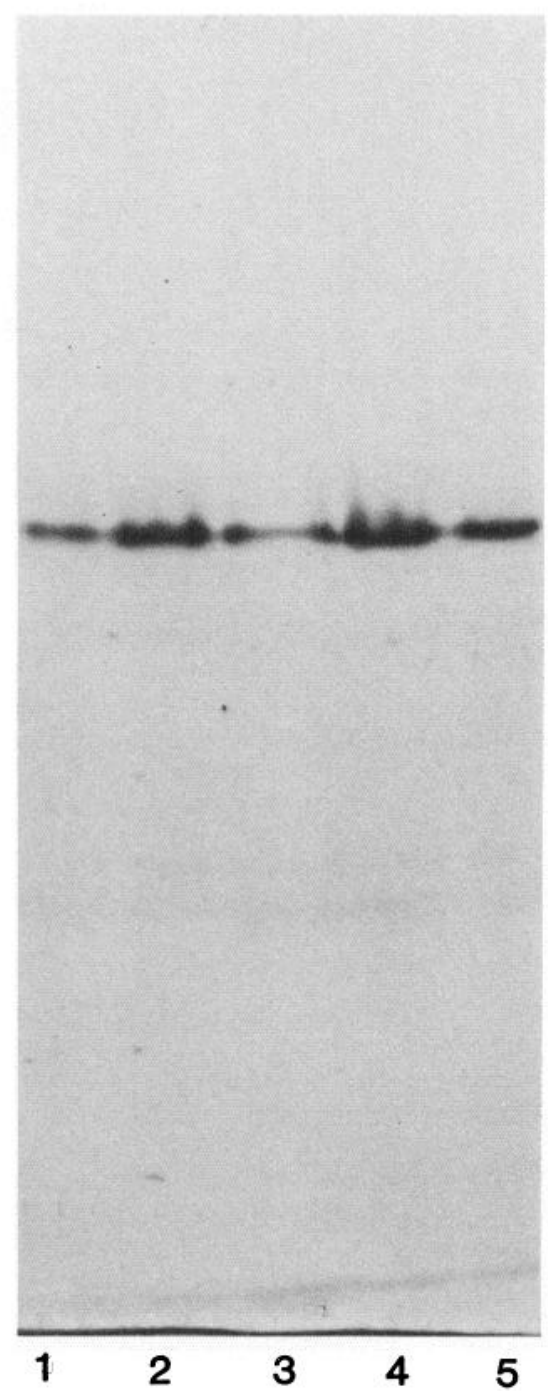

\section{PNS}

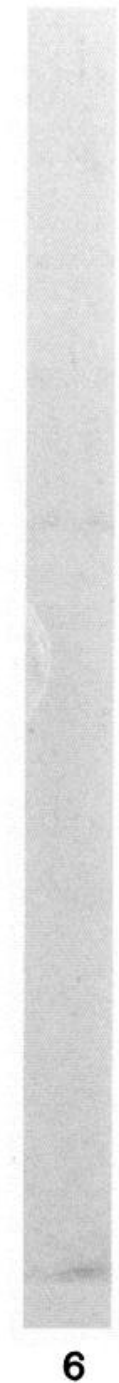

NON NEURONAL

\section{TISSUES}

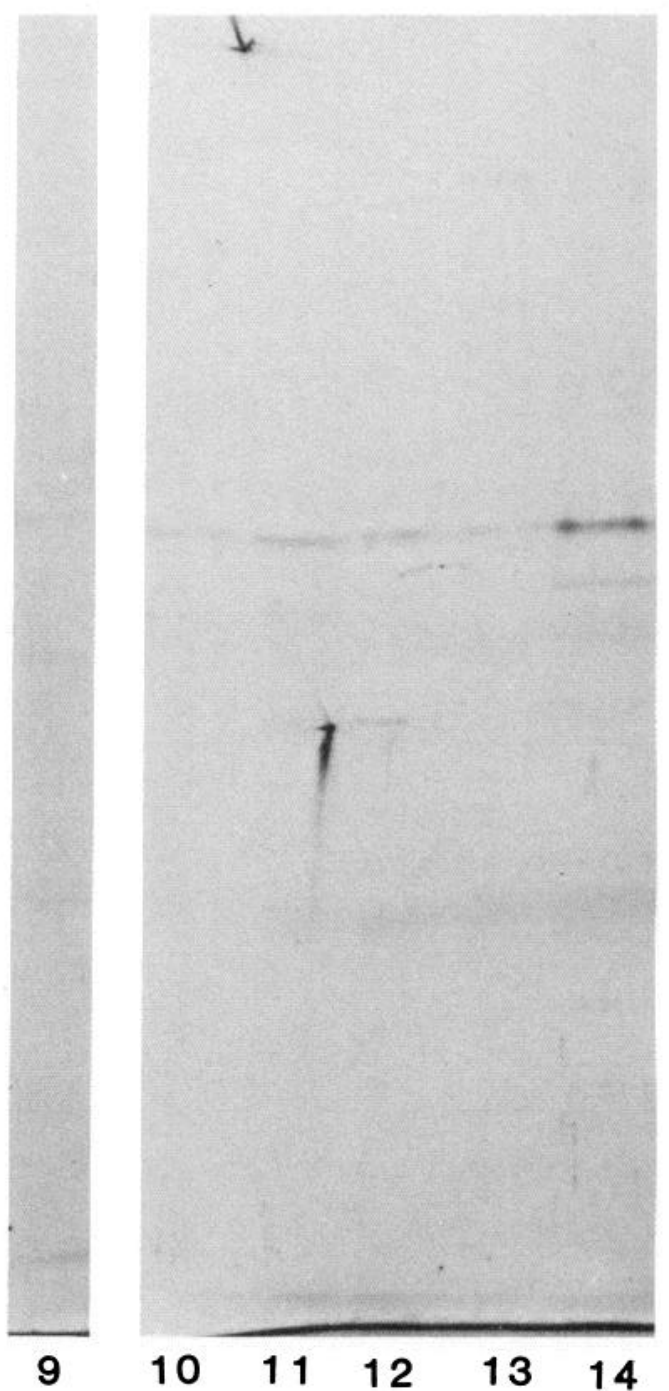

Figure 2. Tissue distribution of the 3D5 antigen in embryonic chicken. Three micrograms of proteins from various tissue samples of an E16 chick were separated by $10 \%$ SDS-PAGE, transferred to nitrocellulose paper, and probed with the 3D5 antibody. Lanes are as follows: 1 , spinal cord; 2 , brain stem; 3 , cerebellum; 4 , optic lobe; 5 , forebrain; 6 , retina; 7 , sympathetic ganglia; 8 , sciatic nerve; 9 , kidney; 10 , aorta; 11 , liver; 12 , skeletal muscle; 13 , cardiac muscle; and 14 , small intestine.

\section{Tissue distribution of the $3 D 5$ antigen}

As the 3D5 antigen is a component of the neuronal membrane cytoskeleton, it was important to determine whether it is present in both the CNS and the PNS and if it is also present in nonneural tissues. As shown in Figure 2, the 3D5 antigen is most abundant in the CNS of an E16 chicken. Lower amounts were present in samples from the PNS, and surprisingly very little was found in the developing retina, despite the fact it is developmentally part of the CNS. There are detectable amounts in non-neural tissues, especially in the small intestine. To establish whether the presence of the 3D5 antigen in non-neural tissues could be due to tissue innervation, we chose to analyze the pattern of antibody staining in a peripherally innervated organ.
The small intestine, which gave the strongest reaction on the immunoblot (Fig. 2) is richly innervated and contains several differentiated cell types in a morphologically identifiable array. This enabled us to identify whether only neuron-containing structures stained for the 3D5 antigen. As shown in Figure 3, the 3D5 antigen stained ganglia of the submucosal (Meissener's) and the myenteric (Auerbach's) plexuses. Axonal projections can be seen penetrating the circular muscle, and connecting the ganglia in radial directions. The remaining structures of the intestine did not stain with the monoclonal antibody. These ganglionic structures are reactive with an anti-neurofilament antibody, at a similar developmental age in the chicken (Gershon et al., 1983; Allsopp and Moss, unpublished observations). 

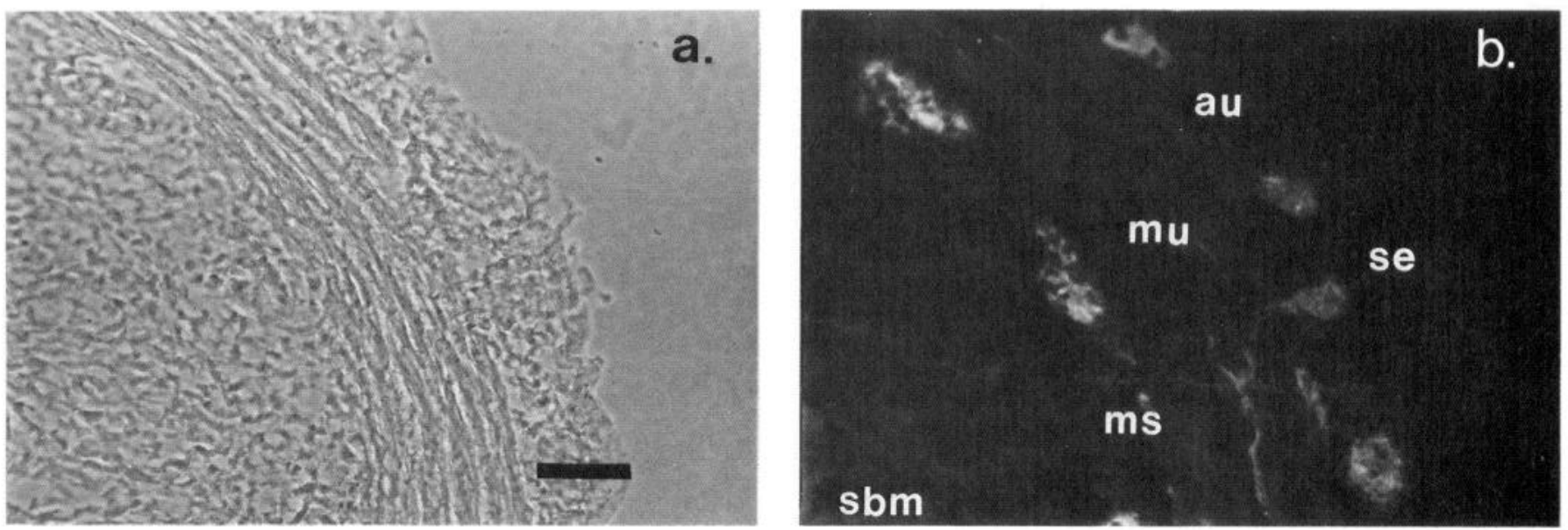

Figure 3. Immunofluorescent detection of innervation to the small intestine. Transverse frozen sections of an E17 chick small intestine were stained with the 3D5 monoclonal antibody $(a$ and $b)$. A pattern of ganglionic staining is observed, with neuronal processes visible within the muscle layer. $a$, Phase contrast; $b$, immunofluorescence. Scale bar, $10 \mu \mathrm{m}$. sbm, submucosa; $m s$, Meissener's plexus; $m u$, circular muscle; $a u$, Auerbach's plexus; se, serosa.

\section{Developmental profile of the 3D5 antigen in chicken brain}

The expression of the 3D5 antigen during development was examined since this might suggest a potential developmental role for the protein. Analysis of brain homogenates by immunoblots revealed the 3D5 antigen to be most abundant in embryonic brain but decreasing in the adult (Fig. $4 A$ ). The proportion of $3 \mathrm{D} 5$ antigen to total protein reached a maximum level in the forebrain and optic lobe at E14, but decreased in the adult to $20-30 \%$ of maximum (Fig. $4 B$ ). In the cerebellum it peaked slightly later, at E15, and decreased in the adult to $50 \%$ of the maximum level. Almost 1.5 times more antigen was detectable, at the respective maximum levels, in the forebrain than in the optic lobe and cerebellum. From the observed profile, the 3 D5 antigen appears to be most abundant during the phase of axonal outgrowth.

\section{D5 antigen is located on the cytoplasmic surface of the neuronal membrane}

It was important to determine if the 3D5 antigen is an integral membrane protein or is associated with membrane components on the cytoplasmic surface of the membrane. By 3 biochemical criteria the 3D5 antigen was judged to be a peripheral membrane protein. As shown in Figure 5, the 3D5 antigen did not bind to a Con A affinity column under conditions where all the Con A-binding glycoproteins are retained. Thus, the 3D5 antigen is unlikely to be glycosylated. Trypsinization of living cultures of sympathetic neurons did not digest the 3D5 antigen under conditions which digested up to $90 \%$ of GP130, a glycoprotein exposed on the surface (Table 1). Intracellular components such as the $70 \mathrm{kDa}$ neurofilament protein were unaffected by this procedure (Ranscht et al., 1984). It is unlikely that a significant portion of the 3D5 antigen is exposed on the surface of neurons. The solubility characteristics of the 3D5 antigen are those expected of a tightly associated peripheral membrane protein; it is largely insoluble in nonionic detergents, high salt, and chaotropic agents such as $\mathrm{KI}$ but is released by the treatment of brain membranes with $0.1 \mathrm{M} \mathrm{NaOH}$ at $4^{\circ} \mathrm{C}$ (Fig. 6). Integral membrane proteins remain in the insoluble fraction, which contains very little of the 3D5 antigen.

\section{Molecular properties of the 3D5 antigen}

The 3D5 antigen has the unusual property of migrating with a different apparent molecular weight on SDS-PAGE according to the percentage of acrylamide. The apparent molecular weight can vary between 43 and $60 \mathrm{kDa}$, as summarized in Table 2 and Figure 7. A Ferguson plot of the mobility of this protein reveals a retardation coefficient for a protein with a molecular weight in the range $30-40 \mathrm{kDa}$. The data suggest that the protein-SDS complex has a lower than expected charge density, perhaps explained by reduced binding of SDS to the protein. Isolation and further characterization of this protein will be required to understand the molecular properties of the 3D5 antigen. Analysis of 2-dimensional gels has shown that the 3D5 antigen is a single component with an acidic pI of 4.4 (Fig. $7 B$ ).

\section{$3 D 5$ stains the neuronal membrane cortex}

The 3D5 monoclonal antibody stained cultures of either sensory or sympathetic neurons but only after the cells have been permeabilized by fixation with methanol at $-20^{\circ} \mathrm{C}$ (Fig. 8). No staining of live cultures was observed, in keeping with the proposed localization of the 3D5 antigen on the cytoplasmic surface of the neuronal plasma membrane. Most cell types in these cultures can be identified by morphology, and by this criterion

\begin{tabular}{lc}
\hline Table 1. Trypsin sensitivity of the 3D5 antigen in cultured neurons \\
$\begin{array}{ll}\text { Incubation time } \\
\text { (min) }\end{array}$ & $\begin{array}{l}\text { Detectable 3D5 antigen } \\
\text { (\%) }\end{array}$ \\
\hline 0 & 100 \\
5 & 59 \\
10 & 86 \\
30 & 91 \\
60 & 103
\end{tabular}

${ }^{a}$ Five-day-old cultures of sympathetic neurons were treated with $1 \mathrm{mg} / \mathrm{ml}$ trypsin at $\mathrm{pH} 7.4$ in $150 \mathrm{~mm} \mathrm{NaCl}, 0.1 \mathrm{M} \mathrm{NaHCO}_{3}$. The reaction was quenched with an equal volume of $1 \mathrm{mg} / \mathrm{ml}$ soybean trypsin inhibitor and $1 \mathrm{mM}$ PMSF.

" Percentage of antigen remaining compared with that present at zero minutes enzyme incubation. Data from densitometric scans of autoradiographs from ${ }^{125}$ Iprotein A detected antibody bands. 
A

Figure 4. Expression of the 3D5 antigen in chicken brain during development. $A$, Developmental expression of the antigen in forebrain samples. Protein, $1.5 \mu \mathrm{g}$, from the forebrain of chickens at various developmental stages was separated by $10 \%$ SDS-PAGE, and the Western blots were probed with the 3D5 antibody. $B$, Graphic representation of the data from quantitation of immunoblots, using reflectance densitometry, for 3 separate parts of the developing chicken brain. A gel loading of $1.5 \mu \mathrm{g}$ (total protein) ensured that quantitation of antibody binding remained within an established linear range. Age given in days. $A$, adult.

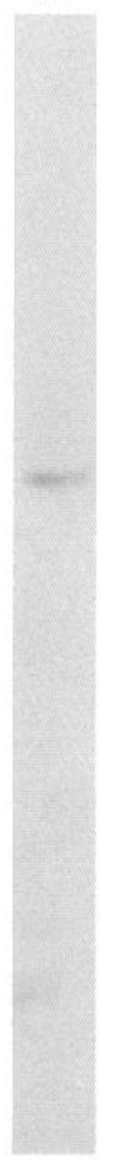

6
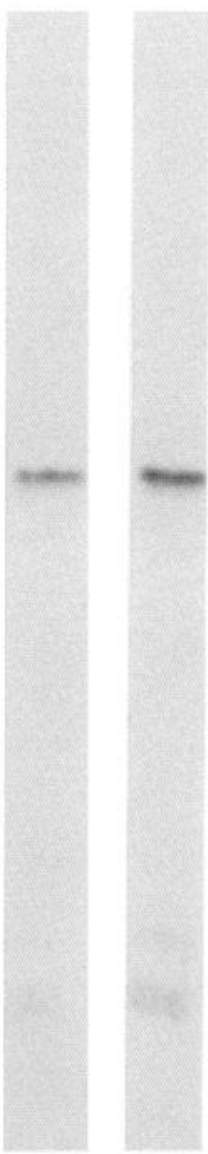

8

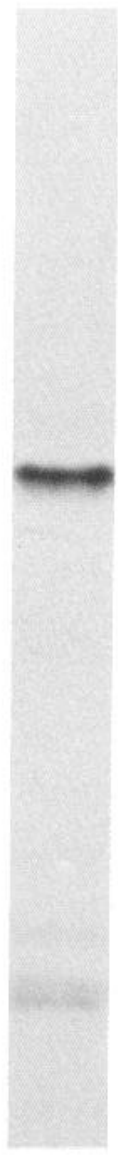

12

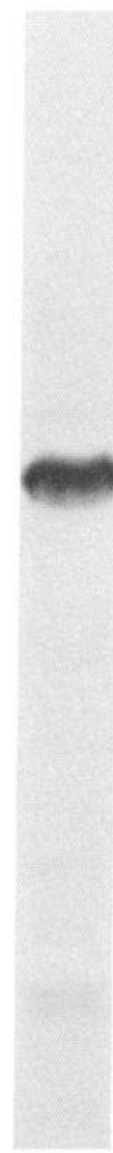

14

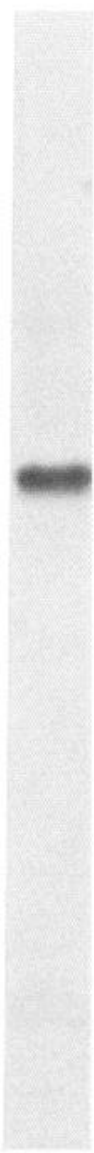

16

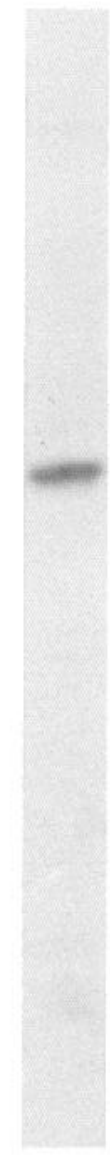

18

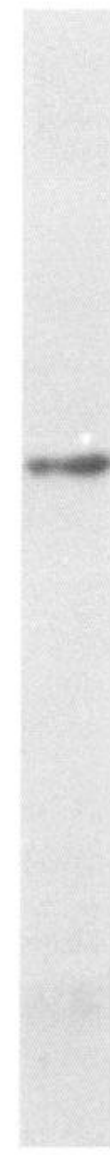

20

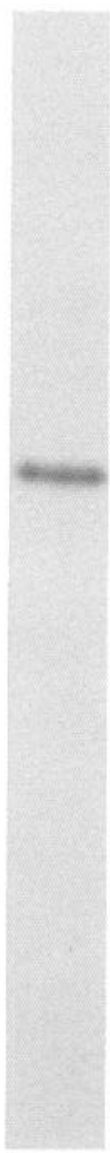

24

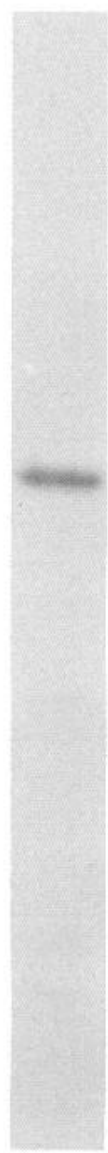

A

\section{AGE OF EMBRYO}

3D5 appears to stain only neurons. This finding is confirmed by the lack of antigen on immunoblots of cultured non-neuronal cells from sciatic nerve (data not shown). 3D5 antigen was localized in all major parts of the neuron, and the staining pattern was typical for a component associated with the cortical, membrane skeleton. Thus, the plasma membrane of the cell soma appears as a ring of fluorescence around the perimeter of the cell, while neurites, if of sufficiently large diameter, show 2 parallel lines of intense fluorescent staining. In addition microspikes, lamellopodia, and the growth cone body are all brightly stained, the base of the growth cone staining with a punctate pattern.

\section{Table 2. Range of apparent molecular weights for the 3D5 antigen}

\begin{tabular}{ll}
$\begin{array}{l}\text { Acrylamide conc. } \\
(\% \mathrm{~T})\end{array}$ & $\begin{array}{l}\text { Apparent molecular } \\
\text { weight }^{a}\end{array}$ \\
\hline 7 & 60 \\
9 & 54 \\
11 & 50 \\
13 & 47 \\
15 & 43
\end{tabular}

${ }^{a}$ Apparent molecular weights estimated from the comparison with a range of standard proteins, according to migrations with respect to the ion front.
The staining pattern obtained with $3 \mathrm{D} 5$ is similar but not identical to that observed for F-actin. The growth cone body does not stain with rhodamine phalloidin and only intermittent staining of the neurite membranes is observed, although the microspikes are stained in a similar manner to that observed for the 3D5 antigen.

\section{Discussion}

The 3D5 antigen is enriched in the membrane cytoskeleton from embryonic chicken brain. This fraction has been characterized previously (Moss, 1983) and shown to contain only a small subset of proteins from the plasma membrane. For example, only about 5 Con A-binding glycoproteins from the many present in the plasma membrane are retained. Preliminary electron microscopy shows that the membrane skeleton contains little in the way of contaminating mitochondrial and other intracellular membranes (unpublished observations). This agrees with direct findings that mitochondria sediment through $50 \%$ sucrose solutions (Babitch et al., 1976) during the preparation of synaptosomal material from chicken brains. The 3D5 antigen is distinct from known cytoskeletal proteins of similar molecular weight such as vimentin and tubulin. Indeed, cytoskeletal proteins like neurofilaments and tubulin, which have a general cytoplasmic distribution, are not enriched in this fraction. Thus, 


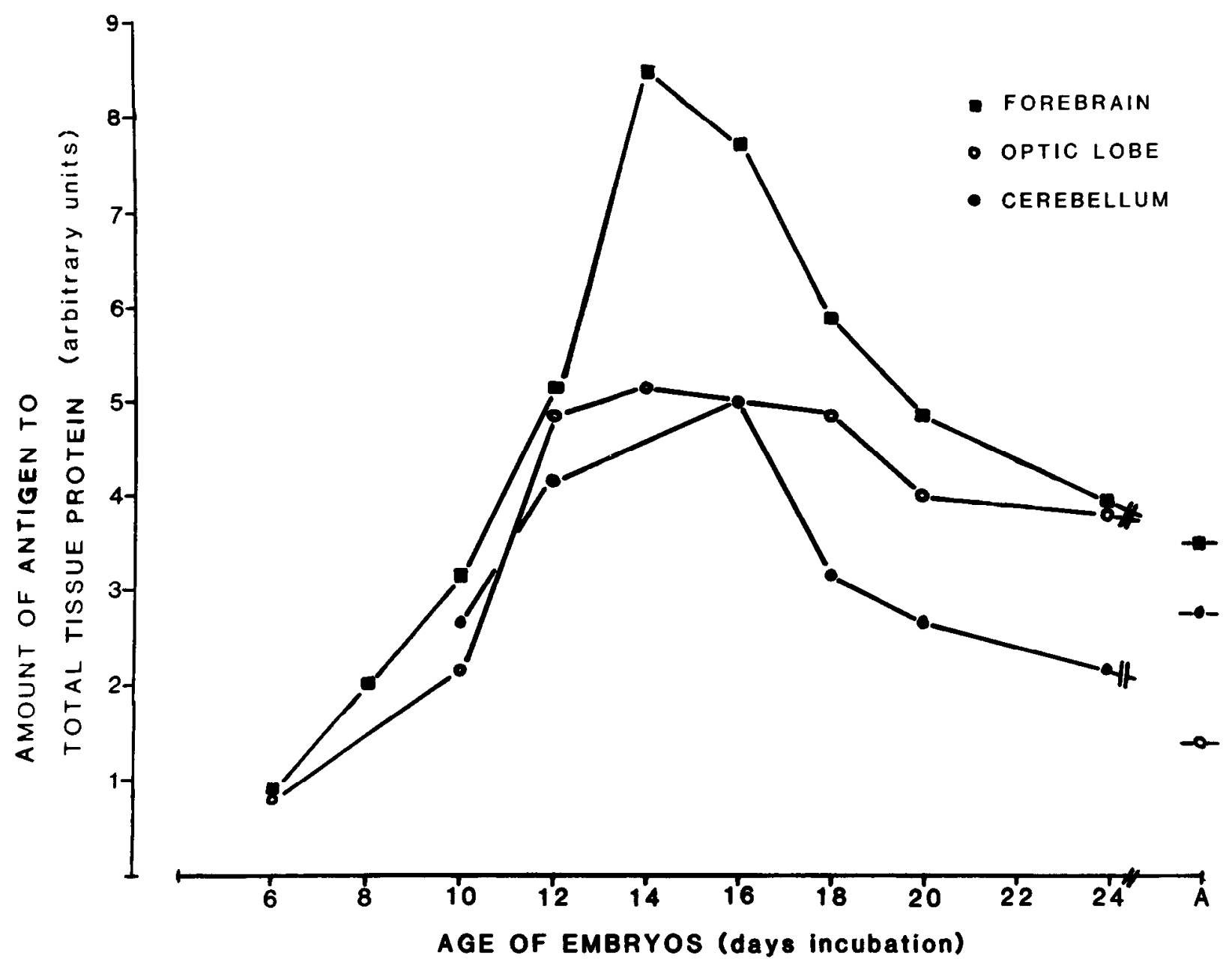

it is apparent that a component like the 3D5 antigen, which shows a 10-fold enrichment in the membrane skeletal fraction, could be a strong candidate for a protein that has a structural role in the neuronal membrane skeleton.

Biochemical evidence suggests it is not an integral membrane protein but is tightly associated with the cytoplasmic surface of the membrane. This result is confirmed by immunofluorescence studies on cultured neurons, which showed that the 3D5 antigen is localized in areas close to the membrane in all regions of the neuron. However, the 3D5 antigen may not be specific to the cell cortex. Although more than $50 \%$ of the 3D5 antigen is associated with the detergent-insoluble membrane skeleton, a proportion of the antigen is soluble under a variety of conditions, which could represent antigen that is not associated with cortical cytoskeletal elements. A similar, although less specific distribution has been suggested for brain spectrin. This protein is reported to be localized just beneath the axolemma in mammalian myelinated axons (Levine and Willard, 1981) but is quite abundant in extruded axoplasm of the squid giant axon, as well as in the subaxolemmal axoplasm (Morris and Lasek, 1984). The relative lack of brain spectrin in the membrane skeleton fraction suggests that it has a lower affinity for the plasma membrane compared with the $3 \mathrm{D} 5$ antigen.

The $3 \mathrm{D} 5$ antigen is most abundant in tissue samples from the
CNS, and further analysis of the embryonic development of the brain reveals an interesting profile of antigen expression. Maximum expression of the 3D5 antigen occurs around E15, a period of extensive fiber outgrowth in all areas of the brain. By this stage, neuronal proliferation has largely ceased and synaptogenesis has begun (LaVail and Cowan, 1971). It is unclear from our experiments whether the abundance of the 3D5 antigen per unit area of neuronal membrane changes with embryonic age or whether the detectable levels of antigen are a reflection of the relative quantities of neuronal membrane in the brain at these varying times during development. It is interesting to note that GP130, a neuronal membrane glycoprotein linked to the membrane skeleton, continues to increase in abundance up to the adult stage (Ranscht et al., 1984), which suggests that the decrease in the expression of the 3D5 antigen is not simply a reflection of decreased levels of neuronal membrane. As the high amounts of the 3D5 antigen coincide with the period of axon and dendrite extension, it is probable that the $3 \mathrm{D} 5$ antigen plays a role in this growth-associated phase of neuronal differentiation. In this context, it should be noted that the 3D5 antigen is particularly abundant in the growth cones of cultured PNS neurons (Fig. 8).

The 3D5 antigen is enriched in the CNS with the exception of the developing retina but is barely detectable in the PNS. 
A

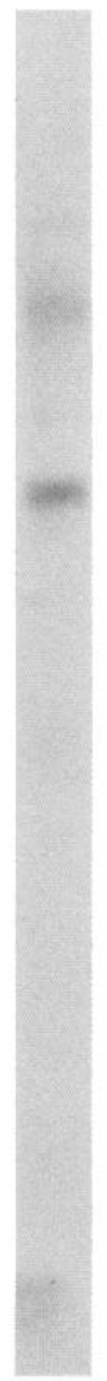

1

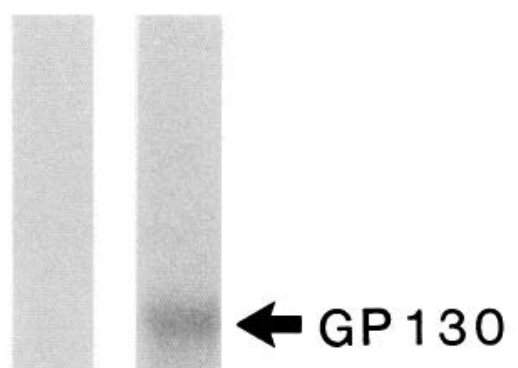

B

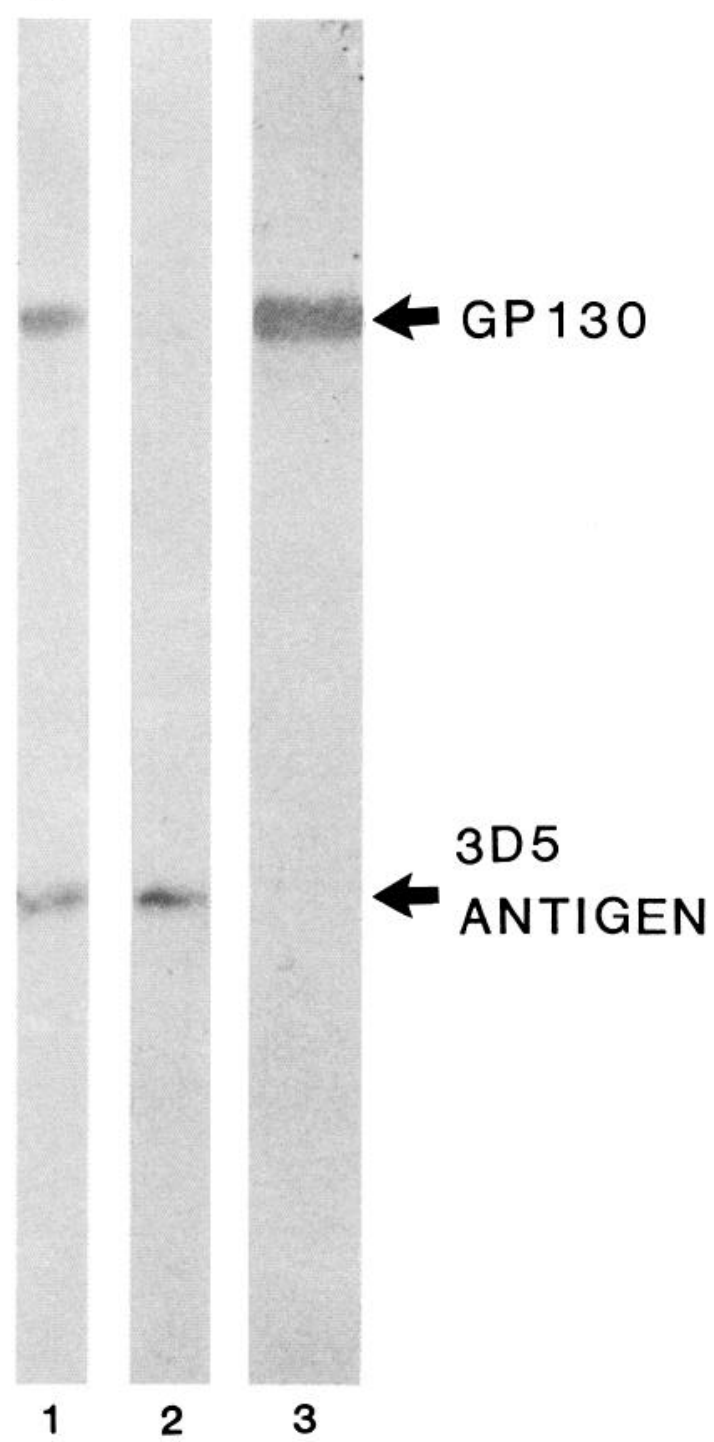

Figure 5. The 3D5 antigen does not bind Con A. Membrane skeletons dissociated with $0.1 \%$ SDS were applied to a Con A-Sepharose affinity column, equilibrated in buffer C. Lanes are as follows: 1, membrane skeleton; 2, unbound material; and 3, material eluted with methyl- $\alpha$-Dmannopyranoside. Fractions were probed with $(A){ }^{125} \mathrm{I}$ Con A or $(B)$ 3D5 monoclonal antibody and anti-GP130.

Since the developmental time course has only been studied for the brain, varying profiles of 3D5 expression for different parts of the nervous system may partly account for this. The presence of the antigen in non-neural tissues is due to innervation, as suggested by the immunofluorescent detection of neural structures in the small intestine. From this analysis and the lack of detectable antigen in non-neuronal cells of the PNS, we conclude that the 3D5 antigen is specific to neurons in the PNS. However, it remains to be proven whether a similar neuronal specificity exists for the localization of the 3D5 antigen in the CNS.

In the presence of SDS, the protein migrates with an apparent molecular weight that can vary by as much as $20 \mathrm{kDa}$ according to the total monomer concentration of the polyacrylamide gels. Extrapolation to zero acrylamide monomer, where the mobility of the protein is a function of charge density rather than size, shows that the $3 \mathrm{D} 5$ antigen has a lower charge density than most standard proteins. The most likely explanation is that the antigen has a lower SDS binding capacity compared with stan- dard proteins. Deviations from the typical binding of SDS to proteins occur when a protein is highly charged (Tung and Knight, 1971; Gahmberg and Andersson, 1981); this would be the case for the 3D5 antigen, which has a very acidic isoelectric point.

As suggested previously, the 3D5 antigen shares several biochemical characteristics with that of the developmentally regulated neuronal protein, GAP 43 (Ellis et al., 1985; Jacobson et al., 1986), but anti-GAP 43 antibody (kindly donated by Dr. $\mathrm{K}$. Meiri) fails to cross-react with any component in embryonic chicken brain. However, the molecular weight range and isoelectric point of GAP 43 are similar to that of the 3D5 antigen. Furthermore, GAP 43 is probably not glycosylated and can be extracted efficiently only at extremes of $\mathrm{pH}$ using $\mathrm{NaOH}$ (Zwiers et al., 1985). It is possible that the 3D5 antigen belongs to a group of growth-associated proteins in chickens, and therefore, its association with the membrane cytoskeleton could be a reflection of the role this protein has in the mechanism of fiber outgrowth. 
A

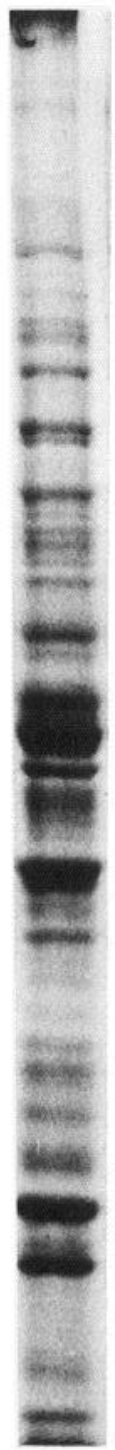

1

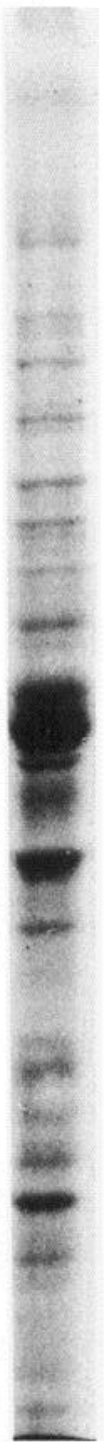

2

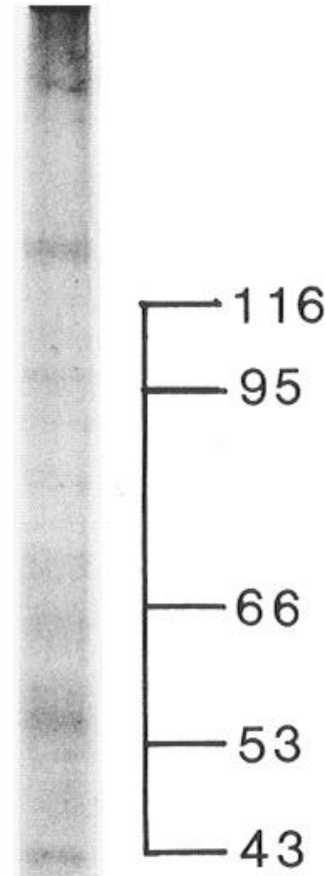

B

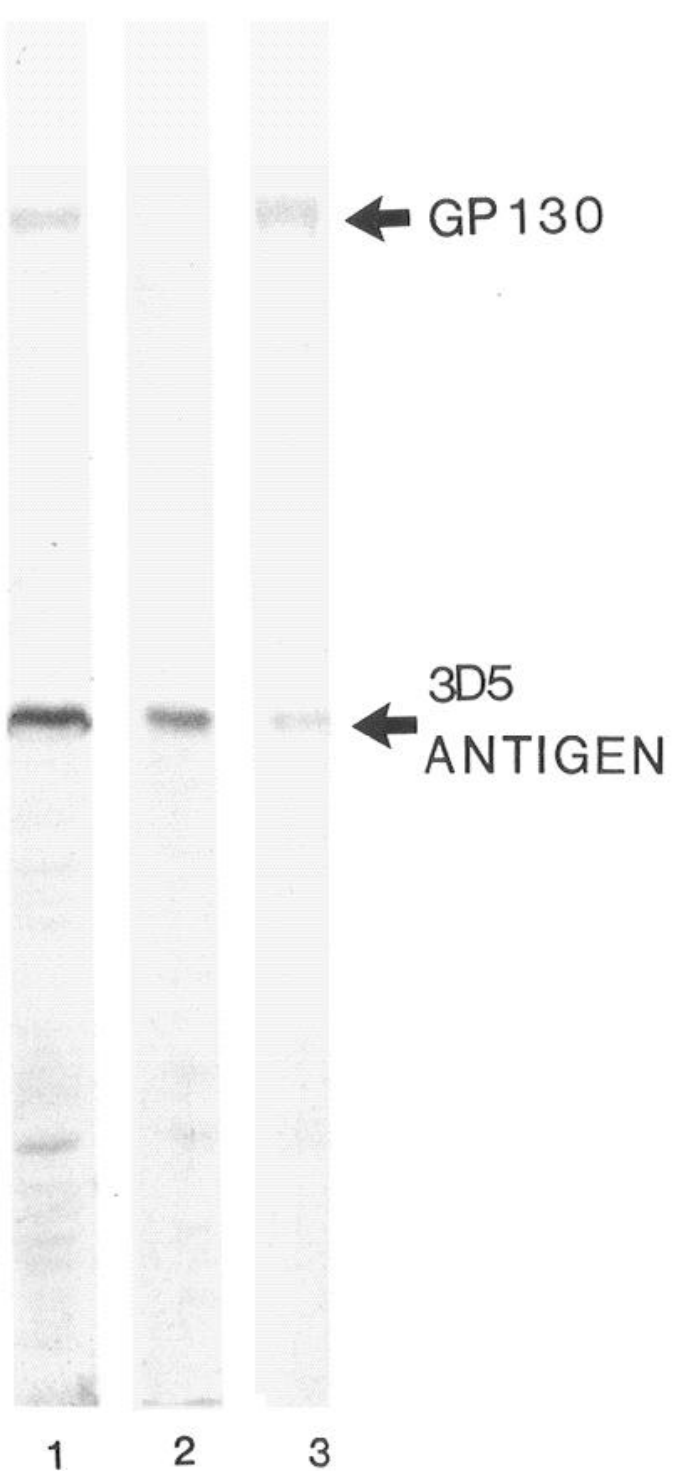

Figure 6. The 3D5 antigen is an extrinsic membrane protein. Membranes from E18 chick brains were treated with $0.1 \mathrm{M} \mathrm{NaOH}$ for 30 min at $4^{\circ} \mathrm{C}$. Following centrifugation at $200,000 \times \mathrm{g}$ for $30 \mathrm{~min}$ at $4^{\circ} \mathrm{C}$, the supernatant was neutralized with $1 \mathrm{M}$ Tris- $\mathrm{HCl}, \mathrm{pH} 7.6$. Lanes are as follows: 1 , membranes; $2, \mathrm{NaOH}$-soluble supernatant; and 3, insoluble residue. Samples were fractionated by $10 \%$ SDS-PAGE $(a)$ Coomassie or $(b) 3 D 5$ monoclonal antibody and anti-GP130 antibody.

The 3D5 antigen is enriched in the neuronal membrane skeleton at a critical stage in development, when axonal and dendritic outgrowth is most prominent. We propose that the 3D5 antigen could be important for the interaction between the membrane skeleton and the overlying membrane. Such an interaction is provided by a class of proteins with similar function which have been identified in neurons-including ankyrin (Bennett, 1985) and brain spectrin, which binds to NCAM 180 (Pollerberg et al., 1986). However, the 3D5 antigen may be the first such protein that is enriched in, if not unique to, neurons.

\section{References}

Babitch, J. A., T. B. Breithaupt, T. C. Chiu, R. Garadi, and D. L. Helseth (1976) Preparation of chick brain synaptosomes and synaptosomal membranes. Biochim. Biophys. Acta 433: 75-89.
Bennett, V. (1985) The membrane skeleton of human erythrocytes and its implications for more complex cells. Annu. Rev. Biochem. 54: 273-304.

Bennett, V., A. J. Baines, and J. Q. Davis (1985) Ankyrin and synapsin: Spectrin-binding proteins associated with brain membranes. J. Cell. Biochem. 29: 157-169.

Bozyczko, D., and A. F. Horwitz (1986) The participation of a putative cell surface receptor for laminin and fibronectin in peripheral neurite extension. J. Neurosci. 6: 1241-1251.

Bramhall, S., N. Noack, M. Wu, and J. R. Loewenberg (1969) A simple colorimetric method for determination of protein. Anal. Biochem. 31: 146-148.

Chan, S. Y., K. Murakami, and A. Routtenberg (1986) Phosphoprotein F1: Purification and characterization of a brain kinase $C$ substrate related to plasticity. J. Neurosci. 6: 3618-3627.

Duhaiman, A. S., and J. R. Bamburg (1984) Isolation of brain $\alpha$-actinin. Its characterisation and a comparison of its properties with those of muscle $\alpha$-actinin. Biochemistry 23: 1600-1608.

Ellis, L., F. Katz, and K. H. Pfenninger (1985) Nerve growth cones 
A

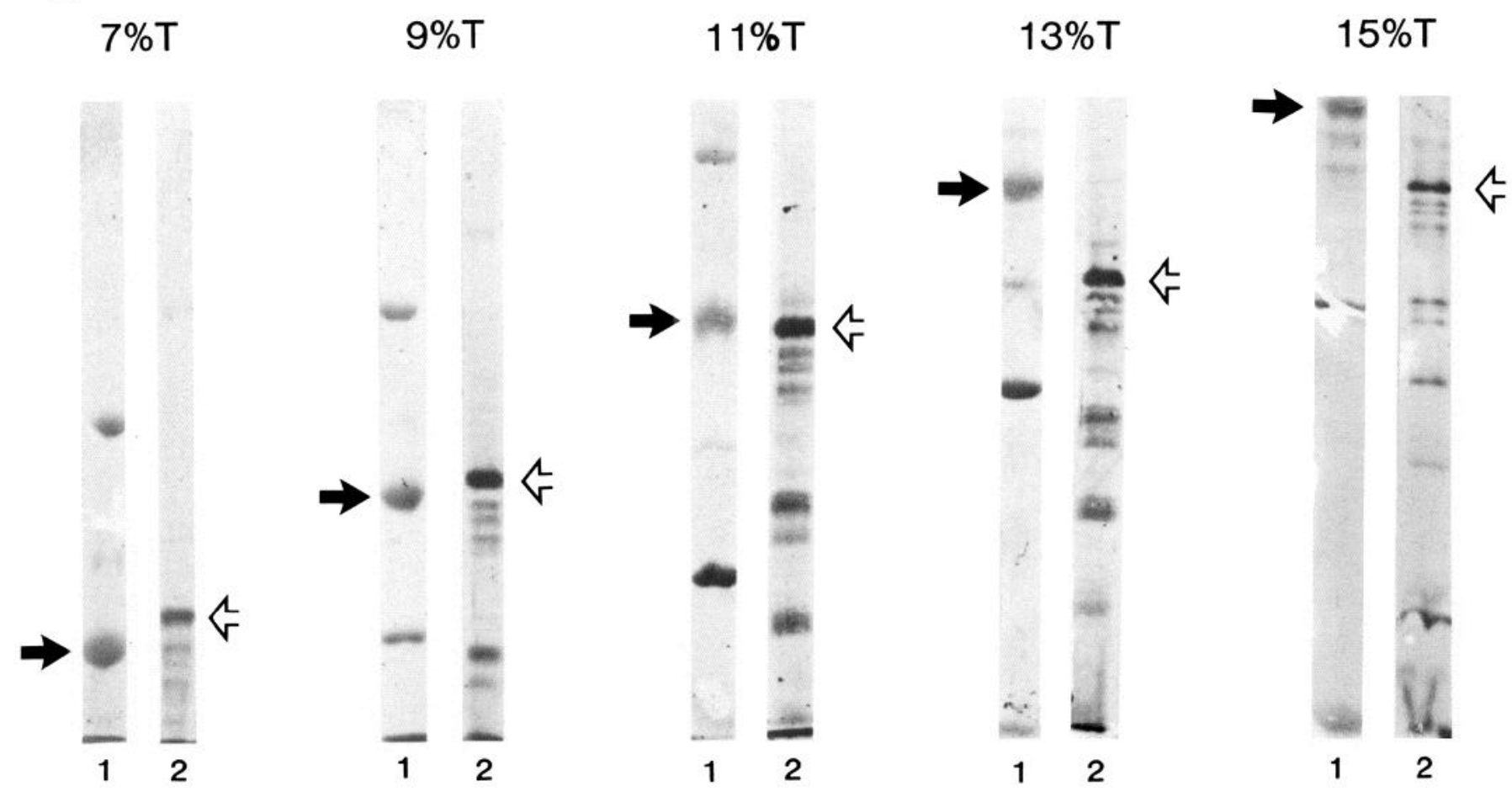

B

IEF

BASE

ACID

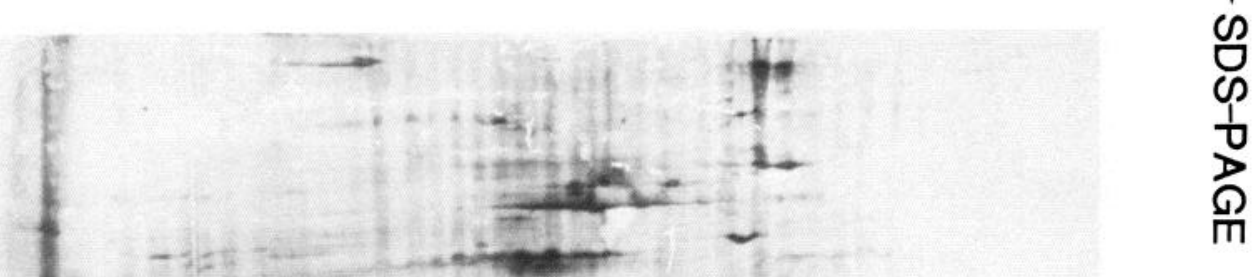

Figure 7. Molecular properties of the $3 \mathrm{D} 5$ antigen. $A$, Anomalous migration in SDS-PAGE. Western blots of $(1)$ molecular weight standards stained with amido black and (2) membrane skeleton probed with the 3D5 antibody and then stained with amido black. The solid arrow indicates the tubulin standard and the open arrow the 3D5 antigen. $B$ Estimation of the isoelectric point for the 3D5 antigen. Western blot of the 2-dimensional SDS-PAGE probed with the 3D5 antibody and then stained for total protein with the Aurodye colloidal gold reagent. The arrow denotes the position of the 3D5 antigen with respect to (I) actin and (2) tubulin isoforms. First- and second-dimensional gel electrophoresis was performed according to the procedures described under Materials and Methods. The duration of electrophoresis during 1-dimensional isoelectric focusing was $5.5 \mathrm{hr}(6000 \mathrm{~V} /$ $\mathrm{hr}$ ). Acidic proteins are located to the right of the blot, basic proteins to the left. The $\mathrm{pH}$ gradient range, measured by soaking tube gel slices in deionized water, is between 4.2 and 7.2. Ten micrograms of total embryonic chick brain lysate were layered onto each tube gel. 

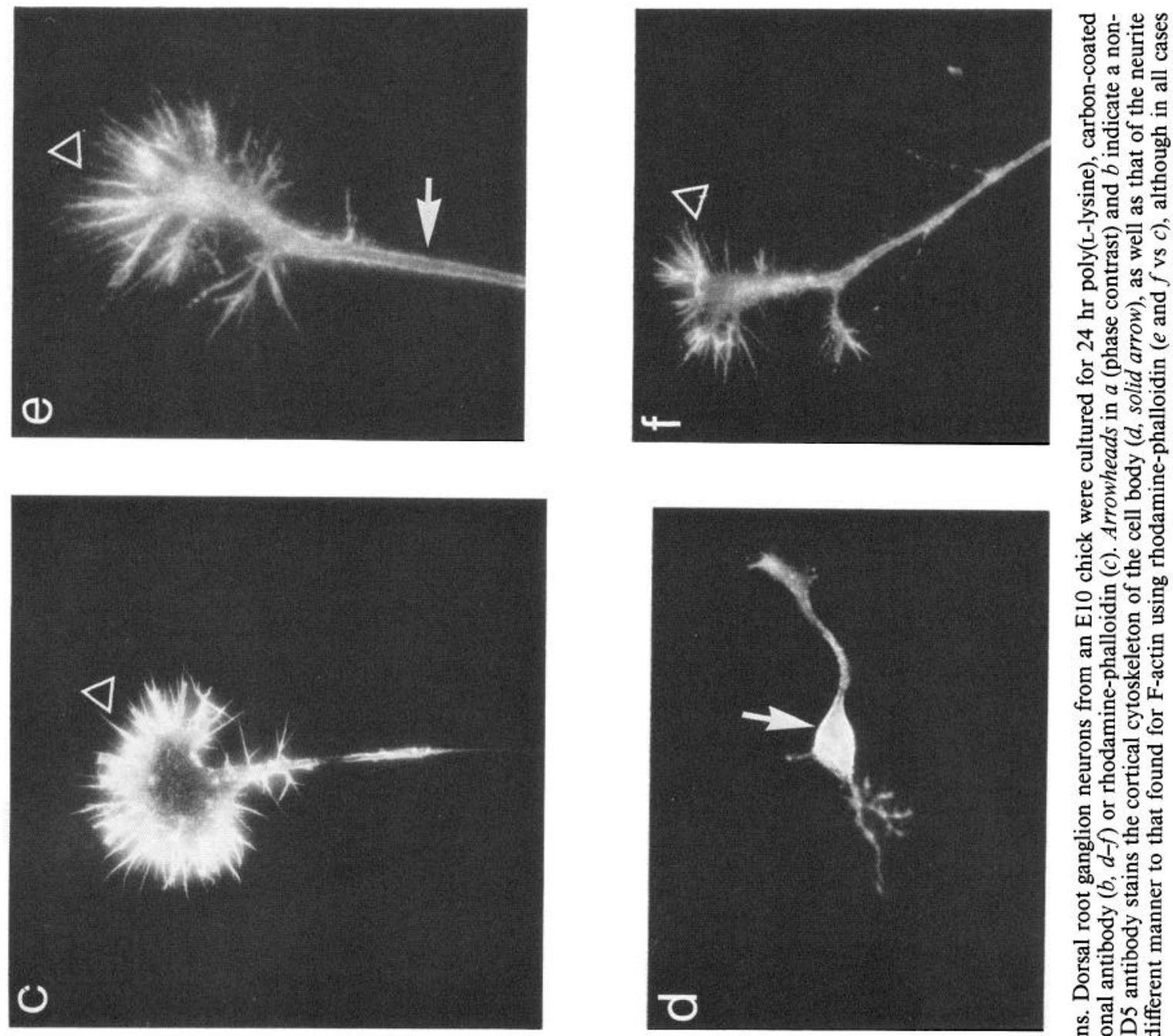

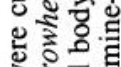
눠융 可重 ㅇ. 뜽.

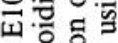
들 근. E 단 운

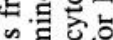

을 t) 돈 응 듀웛 ㄷㅇ a 중

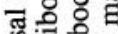

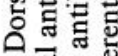
可 我的象

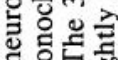
c $\Xi$ 俩

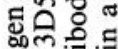
을 空

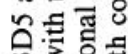
긍 啳 열 . ง न

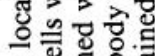
ष्.

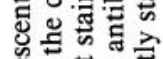
क्षे

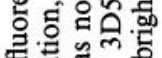
흥 चै

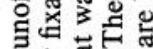
范芷 是安金部 .

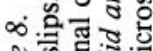
ริ so 
isolated from fetal rat brain. II. Cyclic adenosine $3^{\prime}: 5^{\prime}$-monophosphate (cAMP)-binding proteins and cAMP-dependent protein phosphorylation. J. Neurosci. 5: 1393-1401.

Gahmberg, C. G., and L. C. Andersson (1981) Role of sialic acid in the mobility of membrane proteins containing O-linked oligosaccharides on polyacrylamide gel electrophoresis in sodium dodecyl-sulphate. Eur. J. Biochem. 122: 581-586.

Galfre, G., S. C. Howe, C. Milstein, C. W. Butcher, and J. C. Howard (1977) Antibodies to the major histocompatibility antigens produced by hybrid cell lines. Nature 266: $550-552$.

Gershon, M. D., R. F. Payette, and T. P. Rothman (1983) Development of the enteric nervous system. Fed. Proc. 42: 1620-1625.

Horwitz, A., K. Duggan, R. Greggs, C. Decker, and C. Buck (1985) The cell substrate attachment (CSAT) antigen has properties of a receptor for laminin and fibronectin. J. Cell Biol. 101: 2134-2144.

Horwitz, A., K. Duggan, C. Buck, M. C. Beckerle, and K. Burridge (1986) Interaction of the plasma membrane fibronectin receptor with talin-A transmembrane linkage. Nature 320: 531-533.

Jacobson, R. D., I. Virag, and J. H. P. Skene (1986) A protein associated with axon growth, GAP 43 , is widely distributed and developmentally regulated in rat CNS. J. Neurosci. 6: 1843-1855.

Koehler, G., and C. Milstein (1975) Continuous cultures of fused cells secreting antibody of predefined specificity. Nature 256: 495-497.

Laemmli, U. K. (1970) Cleavage of structural proteins during the assembly of the head of bacteriophage T4. Nature 227: 680-685.

LaVail, J. H., and W. M. Cowan (1971) The development of the chick optic tectum. I. Normal morphology and cytoarchitectonic development. Brain Res. 28: 391-419.

Lazarides, E., and W. J. Nelson (1983) Erythrocyte and brain forms of spectrin in the cerebellum: Distinct membrane-cytoskeletal domains in neurones. Science 220: 1295-1296.

Lazarides, E., and W. J. Nelson (1985) Expression and assembly of the erythroid membrane skeletal proteins ankyrin (goblin) and spectrin in the morphogenesis of chicken neurones. J. Cell Biochem. 27: $423-441$.

Levine, J., and M. Willard (1981) Fodrin: Axonally transported polypeptides associated with the internal periphery of many cells. J. Cell Biol. 90:631-643.
Matsudaira, P., and D. R. Burgess. (1978) SDS microslab linear gradient PAGE. Anal. Biochem. 87: 386-396.

Matus, A. S. (1978) In Methods in Membrane Biology, E. Korn, ed., pp. 203-236, Plenum, New York.

Morris, J. R., and R. J. Lasek (1984) Monomer-polymer equilibria in the axon: Direct measurement of tubulin and actin as polymer and monomer in axoplasm. J. Cell Biol. 98: 2064-2076.

Morrisey, J. H. (1981) Silver stain for proteins in polyacrylamide gels: A modified procedure with enhanced uniform sensitivity. Anal. Biochem. 117: 307-310.

Moss, D. J. (1983) Cytoskeleton-associated glycoproteins from chicken sympathetic neurones and chicken embryo brain. Eur. J. Biochem. 135: 291-297.

O'Farrell, P. H. (1975) High resolution two-dimensional electrophoresis of proteins. J. Biol. Chem. 250: 4007-4021.

Pollcrbcrg, G. E., M. Schachner, and J. Davoust (1986) Surface mobilities of two molecular weight forms of the neural cell adhesion molecule N-CAM are characteristic of distinct differentiation stages. Nature 324: 462-465.

Ranscht, B., D. J. Moss, and C. Thomas (1984) A neuronal surface glycoprotein associated with the cytoskeleton. J. Cell Biol. 99: 18031813.

Shulman, M., C. D. White, and G. Koehler (1978) A better cell line making hybridomas secreting specific antibody. Nature 276:269-270.

Towbin, H., T. Staehlin, and J. Gordon (1979) Electrophoretic transfer of proteins from polyacrylamide gels to nitrocellulose sheets: Procedure and some applications. Proc. Natl. Acad. Sci. USA 76: 43504354.

Tung, J. S., and C. A. Knight (1971) Effects of charge on the determination of molecular weight of proteins by gel electrophoresis in SDS. Biochem. Biophys. Res. Commun. 42: 1117-1121.

Zwiers, H., J. Verhaagen, C. J. van Dongen, P. N. E. de Graan, and W. H. Gispen (1985) Resolution of rat brain synaptic phosphoprotein B-50 into multiple forms by two-dimensional electrophoresis: Evidence for multisite phosphorylation. J. Neurochem. 44: 1083-1090. 